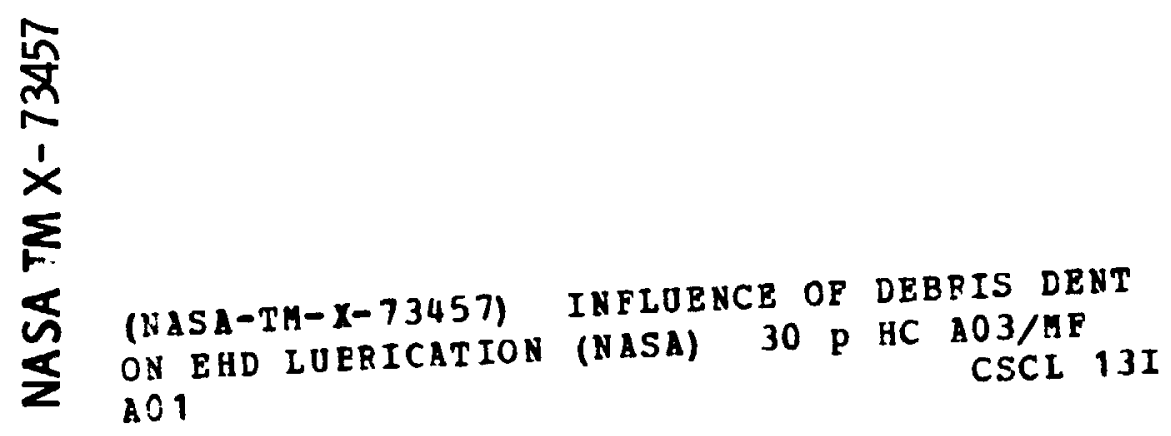

*77-:054 1

Unclas

G3/37 08912

INFLUENCE OF DEBRIS DENT ON EHD LUBRICATION

by Lavern $\mathrm{D}$. Wedeven

Lewis Research Center

Cleveland, Ohio 44135

TECHNICAL PAPER to be presented at

Joint Lubrication Conference cosponsored by the American Society of Lubrication Engineers and the American Society of Mechanical Engineers Boston, Massachusetts, October 5-7, 1976

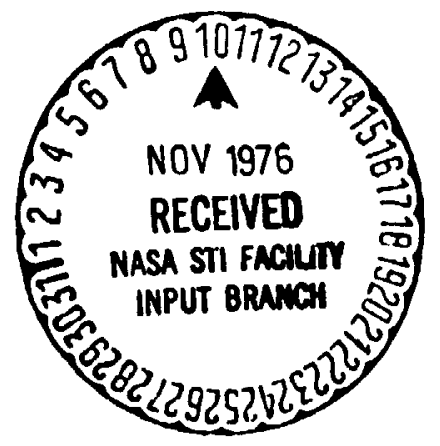




\title{
INFLUENCE OF DEBRIS DENT ON EHD LUBRICATION
}

by Lavern $\mathrm{D}$. Wedeven

NASA-Lewis Research Center

Cleveland, Ohio

\begin{abstract}
Film thickness measurements associated with a debris dent have been made with interferometry under static and dynamic conditions. The presence of a debris dent alters the shape of the inlet region so that the locai film thickness at the leading, edge of the dent can become substantially lower than the trailing edge. The pressure modifications associated with these local EHD effects are in line with the frequent occurrence of surface initiated fatigue spalls originating at the trailing edge of debris dents. The effectiveness of the EHD mechanism in reducing the stress concentrations at the shoulders of the dent is related to inlet dimensions and dent size.
\end{abstract}

\section{INTRODUCTION}

Fatigue spalls of bearing surfaces originate from local regions of plastic strain. These regions may be associated with subsurface nonmetallic inclusions or surface defects such as dents, pits, furrows, nicks, and scratches (1-9). Other surface defects in the form of microcracks and micropits appear to be the result of asperity interaction which can produce local surface distress (glazing or peeling) $(5,10-12)$. The fatigue life of rolling element surfaces is assumed to be determined by a competition between the various modes of crack initiation and propagation $(4,11)$.

Improved steels made by vacuum melting processes have fewer and smaller nonmetallic inclusions. This has contributed substantially to the improvement in fotigue life because of fewer subsurface inclusion initiated fatigue spalls. Consequently, the occurrance of surface initiated fatigue associated with 
local defects (dents, furrows, etc.) has become more frequent (2). This has precipitated a greater interest and concern for tise effects of lubricant contamination and the development of debris dents $(13,14)$.

Under dry contact conditions it is easy to understand how the stress concentrations associated with surface defects can cause surface initiated fatigue spalls. The influence of EHD effects is not entirely clear. The purpose of this paper is to show how local EHD effects can influence the film thickness (and, therefore, pressure and stress) associated with a debris dent.

\section{NOMENCLATURE}

a

$\mathrm{h}_{\mathrm{b}}$

$\mathrm{h}_{0}$

$R$ reduced radius of contact, $1 / R=1 / R_{1}+1 / R_{2}$

$R_{1}, R_{2} \quad$ radius of contacting bodies

$\mathrm{S}_{\mathrm{f}} \quad$ inlet distance defined in eq. (2)

$\lambda$ ratio of film thickness of surface roughness $\left(\lambda=h_{0} / \sigma\right)$

$\sigma \quad$ combined surface roughness, $\sigma=\left(\sigma_{1}^{2}+\sigma_{2}^{2}\right)^{1 / 2}$

$\sigma_{1}, \sigma_{2} \quad$ surface roughness of individual bea ring surfaces

$\varphi$

cha racteristic inlet angle defined in eq. (3)

EXP ERIMENTAL APPARATUS

Film thicknesses were made using optical interferometry. The optical elastohydrodynamic appa ratus is shown in figure 1 and described in detail elsewhere $(15,16)$. The basic components of the apparatus consist of a ball which rides against a transparent disk. 
The EHD film thickness between these surfaces was measured by optical interferometry. Fringes of very good visibility were obtained by using a 17-percent-reflecting layer of chromium on the bearing surface of the transparent disk. Interference measurements were made with wavelengths of two colors (red and green). These were obtained by using a special filter and a xenon flash lamp as a light source. The details of this system and its calibration are described more fully in $(17,18)$. All measurements were carried out at room temperature $\left(23^{\circ} \mathrm{C}\right)$.

\section{TEST MATERIALS}

The test bearing specimens a re shown in figure 2 . The ball is 0.02063 meters in diameter and made of AISI 52100 steel. Its nominal surface roughness is better than $0.018 \mu \mathrm{m} \mathrm{rms}(0.7 \mu \mathrm{in}$.) and its hardness is approximately $60 \mathrm{Rc}$. Other mechanical properties are shown in table I. The transparent disk is 0.102 meter in diarnete $r$ and made of sapphire. It's mechanical properties a re given in table I.

The test ball was supported by three bearings located in a lubricant reservoir shown in figure 2. The rotation of the support bearings continuously supplies lubricant to the test ball.

Most of the tests were performed with a synthetic paraffinic oil that was designated by the manufacturer as XRM109F3. Other tests were performed with a bigh viscosity traction fluid designated by the manufacturer as MCS1218. The properties of the test fluids a re given in table II.

\section{DESCRIPTION OF SURFACE DEFECT}

The surface defect that was studied under static and dynamic conditions is shown in the photomicrograph of figure 3. It can be classified as a debris dent. It is belleved to have been formed during previous testing (16). Several such dents, mostly of smaller size (depth and width) were observed on the ball track. No apparent damage was obse rved on the mating sapphire disk which is a much harder material. 
A stylus trace across the dent center is shown in figure 4 . The stylus was rotated about an axis concentric with the ball center so that the ball curvature could be eliminated. The dent is very shallow, being approximately $80 \mu \mathrm{m}$ wide and $0.8 \mu \mathrm{m}$ deep. One side of the dent is more sharply sloped than the other. The maximum slope is less than $3^{\circ}$. A very slight built-up edge appears at the shoulder of the more steeply sloped side of the dent.

The size of this defect is slightly larger than those discussed by Tallian $(13,14)$ but its depth and width is very similar to that of a typical grinding furrow reported by Chiu and Liu (19) and Chiu et al. (3). In addition, the width of the dent is very similar to that shown by Parker and Zaretsky (8) to have caused a surface initiated fatigue spall. It is of interest to note that the width of the dent $(80 \mu \mathrm{m})$ is on the order of ten times the mean asperity spacing obtained from a typical profile trace across a bearing ring surface (7).

\section{STATIC EXPERIMENTS}

Figures 5 and 6 show the dent under dry contact conditions for two loads.

The maximum Hertzian pressures, assuming smooth surfaces, are respectively $0.34 \times 10^{9} \mathrm{~N} / \mathrm{m}^{2}(50000 \mathrm{psi})$ and $1.2 \times 10^{9} \mathrm{~N} / \mathrm{m}^{2}(175000 \mathrm{psi})$. The actual maximum pressure which will be located at the dent shoulders will be much greater than this (19).

Using the interference fringes which form within the dent it is possible to plot the dent shape under various conditions. The dent shapes which will be shown have been measured along a line which is perpendicular to the axis of rotation of the ball and which passes through the deepest portion of the dent.

The cross-sectional shape of the dent for the two loads of figures 5 and 6 are plotted in figure 7. Because the dent is very much wider than it is deep the vertical scale has been expanded. The high load is seen to deform the dent so that the maximum surface separation is 30 percent smaller than the depth of the undeformed dent. In addition, the deformation at the dent shoulder, under the higher load, causes the surfaces to meet at a much sharper angle. 
Figure 8 shows a photomicrograph of the dent in the presence of the synthetic paraffinic lubricant. More fringes are formed within the dent because the fluid has a higher refractive index than air. The load $(37.8 \mathrm{~N})$ is the same as in figure 6. A comparison of the cross-sectional profiles between the dry and lubricated case are shown in figure 9. The pressure, and therefore, the refractive index within the dent under lubricated conditions are not known. The solid curve corresponds to a refractive index at atmospheric pressure and the dashed curve corresponds to a refractive index at a pressure equal to the maximum Hertzian pressure for smooth surfaces.

Comparing the dry and lubricated dent cross-sections in static contact it is apparent that with no lubricant present the deformation around the dent is greater than is realized in the presence of a lubricant. The lubricant appears to become entraped and compressed within the dent and thereby reduces the deformation.

\section{DYNAMIC EXPERIMENTS}

Observations were made of the debris dent as it passed through the conjunction region. This was accomplished by taking high-speed single flash photomicrographs. The xenon flash lamp was synchronized with the ball rotation and could be modified in such a way as to allow the dent to be photographed in various positions within the conjunction region.

Figure 10(a), (b), and (c) show photomicrographs of the dent in th ree different positions. The central film thickness $\left(h_{0}\right)$ is approximately $0.14 \mu \mathrm{m}$ which is on the order of six times smaller than the depth of the dent. The maximum Hertzian pressure, assuming smooth surfaces, is $1.2 \times 10^{9} \mathrm{~N} / \mathrm{m}^{2}$ $(175000 \mathrm{psi})$ and the surfaces are in pure rolling $(u=0.0134 \mathrm{~m} / \mathrm{s})$. The crosssectional shapes of the dent at the various positions are shown in figure 11 (a), (b), and (c).

When the dent is in the inlet region as shown in figure 11(a) it completely alters the converging geometry associated with the inlet. The dashed line in 

(b), and (c). The same general features again appear. That is, a film thickness reduction is observed at the leading edge as shown in figure 14 (a) and (b) and figure 15(a) and (b). When the rolling direction is reversed, as shown in figures 14 (c) and 15(c) a reduction in film thickness at the leading edge is again observed but is less pronounced due to the reasnlis stated above.

Figure 16 shows the dent under conditions where the central film thickness $\left(\mathrm{h}_{0}\right)$ is $0.78 \mu \mathrm{m}$ which is approximately equal to the depth of the dent. A high viscosity traction fluid, described in table II, was used in this case so that the dent could be photographed under speed conditions which were compatible with the flash duration of the light source.

While a film thickness reduction is again observed at the leading edge of the dent it does not appear to be as great in magnitude as the film thickness reduction measured under the smaller film thickness conditions of figure 11.

\section{COMPARISON OF STATIC A ND DYNAMIC RESULTS}

There is very strong evidence that surface initiated fatigue is associated stress concentrations at the shoulders of dents, scratches, and furrows $(1,2,19)$. The contact problem of an idealized surface furrow under dry contact conditions has been studied by Chiu and Liu (19). Their analysis reveals that a rise in contact pressure occurs at the furrow shoulders and that high shear stresses relatively close to the surface occur below the shoulders. The pressure rise is shown to be a function of the maximum Hertzian pressure. the combined elastic modulus and the dimensions of the furrow. An important furrow dimension is the radius of the shoulder. If it is assumed that the plane strain analysis of (19) can be applied to the dent considered here, the pressure rise at the dent shoulder for dry contact conditions would be on the order of two or three times the Hertzian contact pressure.

From the stancipoint of fatigue an important consideration is the influence of EHD phenomena on the pressure and stress environment at the dent shoulder. 
While pressure and stress calculations have not been made it is possible to deduce the modifying trends caused by local EHD effects. This can be accomplished by comparing the dynamic film thickness measurements of the dent with the static dry contact dent profile and the undeformed dent profile (stylus trace).

The static measurements of the heavily loaded dry contact shown in figure $7 \mathrm{can}$, for comparison purposes, be considered as a severe stress condition. The heavily loaded condition corresponds to the same load used in the dynamic experiments where the maximum Hertzian pressure, assuming smooth surfaces, is $1.2 \times 10^{9} \mathrm{~N} / \mathrm{m}^{2}(175000 \mathrm{psi})$.

The interference fringes measure the separation between the surfaces and not the absolute deformation. The gap between the surfaces within the dent is a result of the deformation of both the steel ball and the sapphire disk. Since the steel ball has an elastic modulus approximately one half that of sapphire it will elastically deform to a greater degree than the sapphire.

If there were no EHD effect on the pressure distribution around the dent under lubricated conditions we would expect the dent shape to look like that of the heavily loaded profile of figure 7 with an additiona! feature or the presence of a uniform film thickness $\left(h_{0}\right)$ separating the surfaces. The pressure distribution a round the dent would be identi cal to that of the dry contact case. That is, the pressure within the cavity created by the dent will be zero and there will be a pressure rise of two or three times the Hertzian pressure around the shoulder of the dent.

This heavily loaded dry contact profile is compared with the lubricated profile in figure 17 where the central film thickness is $0.14 \mu \mathrm{m}$. The two profiles ha:e been superimposed so that the deepest point of the dent on each profile coincides. Comparison of the two profiles shows that the dent is not as severely deformed under lubricated conditions as it is under dry contact conditions. In addition, there is less deformation at the leading edge of the dent than the trailing, edge. 
9

In figure 18 the undeformed dent profile obtained from the stylus trace is compared with dent profile under the dynamic conditions of figure 17 . In contrast with the dry contact profile, the undeformed profile can be thought of as representing the dent shape where the influence of EHD has created a pressure environment around the dent which allows the dent to pass through the Hertzian region in an "undeformed" state: i.e., the pressure a round the dent is everywhere equal to the Hertzian pressure for smooth surfaces. Comparing the profiles of figure 18 shows that under dynamic conditions where the film thickness is $0.14 \mu \mathrm{m}$ the local deformation a round the dent is significantly greater than its undeformed condition.

Figures 19 and 20 compare respectively the dry contact and undeformed dent profiles with the dent profile under much larger film thickness conditions $\left(\mathrm{h}_{0}=0.78 \mu \mathrm{m}\right)$. Under these larger film thickness conditions the deformation a round the dent is far less than the dry contact case shown in figure 19 and approaches very closely the undeformed profile as shown in figure 20.

\section{DISCUSSION}

The experimental observations and measurements provide a reasonably clear understanding of the EHD phenomena associated w:th the presence of a surface defect such as the debris dent considered here. Under pure rolling conditions the local FHD film thickness in and around the dent a re developed during its passage through the inlet region. The dominating influence that the inlet region has on film thickness is well established $(17,20)$. The additional feature illustrated here is that EHD effects a re very local in nature. The local film thickness that is associated with a given element in the Hertzian region is the result of the integrated hydrodynamic pressure that element has r,ncountered while passing th rough the inlet region. If a surface defect substantially modifies the shape of the inlet region as shown in figure 11 (a) it will also modify the local hydrodynamic pressure generation and local film thick- 
ness within that region. Because the surface modification at the leading edge of the dent is less favo rable for pressure generation than the trailing edge the local film thickness is observed to be slightly luwer at the leading edge than it is at the trailing edge.

Because of the importance of the inlet region it is instructive to compare the characteristic inlet dimensions with the dimensions of the debris dent. The inlet region can be defined as the region upstream of the Hertzian region where significant hydrodynamic film forming pressure is generated. The inlet region has a finite size which varies with the thickness of the central film thickness $\left(h_{0}\right)$. Il. the work on starvation (17) two inlet dimensions $\left(S_{f}\right.$ and $\left.h_{b}\right)$ as shown in figure 21 were used to describe the bounda ries of the inlet region. The dimension of $h_{b}$ can be thought of as the thickness of the inlet region gap where significant hydrodynamic pressure commences, and the dimension of $\mathrm{S}_{\mathrm{f}}$ can be thought of as the distance over which the inlet pressure is generated. As shown in (17) these inlet dimensions a re related to $h_{0}$ in the following way

$$
\begin{gathered}
h_{b}=-9 h_{0} \\
S_{f}=3.52 \frac{\left(R h_{0}\right)^{2 / 3}}{a^{1 / 3}}
\end{gathered}
$$

Values of $h_{b}$ and $s_{f}$ for the three cent ral film thicknesses used in the experiments are shown in table III. For the film thickness range considered here $s_{f}$ is between one and two orders of magnitude larger than $h_{b}$ indicating that the convergent inlet region is a great deal longer than it is thick. This feature is characteristic of many debris dents. The one considered here is much longer $(80 \mu \mathrm{m})$ than it is deep $(0.8 \mu \mathrm{m})$.

If a characteristic inle ${ }^{+}$convergence angle $\varphi$ is defined as illustrated in figure 21 it can be shown that 


$$
\varphi=\arctan \approx .27 \frac{\left(\mathrm{ah}_{0}\right)^{1 / 3}}{\mathrm{R}^{2 / 3}}
$$

Values of the inlet angle $\varphi$ for the three experimental film thicknesses, as shown in table ill, are very small. on the order of one degree. Tnis is smaller than the ayerage asperity slope of many bearing surfaces. It is also smalle1 than the maximum slope within the debris dent $\left(2.7^{\circ}\right)$. The data in table III shows that the physical size of the inlet region, measured in terms of $h_{b}, s_{f}$, and $\varphi$. increases with the central film thichness $\left(h_{0}\right)$. Is the inlet iegion becomes larger the film forming hydrodynamic pressure generation as sociated with this region becomes less affected by local surface defects. This is why the dent profile under the la rger film thickness condition of figu re 20 approaches that of the undeformed profile measured by the stylus trace.

The EHD phenomenon in the inlet region presents the dent to the llertzian region with a fixed film thickness distribution that does not change while passing through the Hertzian region. There is no "leakage" of the fluid and loss of film thickness as is frequently stated. The reduction of film thickness is a resilt of the loss of local EHD pressure generation while passing through the inlet region.

When ile dent reaches the Hertzian region it is subjected to a very high pressure environment. While the film thickness around the dent remains relatively fixed during its passage through the Hertzian region the absolute pressure may vary considerably.

When the central film thickness is very small, approaching that of the dry contact case of figure 6 . the local pressure around the dent shoulders may be substantially above that of the Hertzian pressure for smooth . Irfaces while the pressure within the dent cavity may be substantially below the Hertzian pressure for smooth surfaces. The pressure peak at the dent shoulders will create a local stress concentration slightly below the surface which may 
eventually lead to "surtace initiated" spalling fatigue (19).

When the central illm thickness is relatively lange as shown in figure 16 there is considerably less local elastic deformation around the dent shoulders as shown in figure 19. That is, the dent approaches the undeformed shape. This implies that the pressure a round the dent will approach that of the casc for smooth surfaces and that local stress wneentration at the dent shoulders will be sunstantially reduced from the dry contact case.

An intermediate central film thicknese as shown in figure 11 results in a condition where the EHD filın thicknoss modifications are slightly different for the leading and trailing edges of the dent. The local reduction in film thickness at the leading edge must be accempanied by a reduction in pressure and stress concentration. The trailing edge, however. does not receive the same benefit. Tilese fiim thichness measurements may be a cont ributing iactor in connection with the frequent observations of surfice initiated fatigue spalls originating at the trailing edge of debris dents (1, 2). Figure 22(a) and (b) shows typical fatigue spills which have originated at the trailing edgess of debris dents. These fatigue spails a re from the inner races of 207 -size drep groove ball bearing tests reported by parker (9). Figure 22(b) and (c) show debris dents from the sane bea ring test program. Microcracks can clearly im scen at the trailing edge of the dents. An adritional feature shown in figure 2a(d) is the surface glazing at the leading, erlge and sides of the dent. Such glazingr. which roes not appear at the trailing edge, must correspond to the lower film thickness which occurs at the leading, edge and sides of the dent as shoun in figure 10. This type of glazing or peeling is very frequently observed at the edges of dents. furrows, and scratches. If the $\lambda$ ratio $\left(h_{0} / O\right)$ is smali the glazing would be expected to appear on all sides of the indentid jefect. A larger $\lambda$ ratio is expected to show surface glazing only at the leading edge like that of figure 22(d). This type of information maly be helpfil duning post-test evaluations. 
The present study has concentrated on pure rolling conditions. If sliding as well as rolling is present additional EHD effects appear. Figure 23 and figure 24 show the film thickness distribution around the dent under conditions where the ball surface, which contains the dent. is muving faster than the sapphire disk. Local film thickness modifications occur at the converging and diverging sides of the dent as a result of the EHD effects asscciated with the relative surface velocity while passing through the Hertzian region. When the dent profile is compared with the undeformed profile as shown in figure 24 there appears to be a substantial increase in film thickness on the trailing side of the dent. This local increase in deformation due to sliding is in line with the results reported by Jackson (21) and Cheng (22). The presence of sliding may increase the stress concentration at the trailing edge. The leading edge, according to Chiu (3) may benefit from a reduction in local pressure under sliding conditions. These EHD effects associated with sliding will be located on the opposite sides of the dent for the case where the indented ball surface is moving slower than the sapphire disk. The implication that the presence of sliding creates additional pressure and stress concentration is in line with the detrimental effect sliding has on surface initiated fatigue (1) and the existence of pressure rippling (23).

\section{CONCLUSIONS}

The film thickness measurements associated with a debris dent under the static and dynamic conditions considered here lead to the following conciusions:

(1) Comparison of the dry and lubricated dent profiles in static contact shows that the elastic deformation associated with the dent is reduced by the lubricant trapped within the dent cavity.

(2) Under dynamic conditions the amount of elastic deformation associated with the dent varies with the central film thickness. As the central film thickness increases the dent approaches its undeformed shape. 
(3) A reduction in film thickness can occur at the leading edge and sides of the dent. This can be explained by the local EHD pressure modifications the dent has created during its passage through the inlet region.

(4) For pure rolling, the EHD effects associated with a debris dent is determined by the degree of modification the dent introduces to the shape of the inlet region. The size of the dent can be compared with the physical size of the inlet region using the characteristic inlet dimensions derived previously for lubricant starvation.

(5) The measurement of the dent profile under increasing film thickness conditions leads to the implication that the pressure and stress concentration associated with the shoulders of the debris dent is gradually relieved as the film thickness increases. In addition. the leading edge of the dent is relieved to a greater extent than the trailing edge.

(6) The measurement of a dent profile under conditions of sliding as well as rolling indicates the possibility of very substantial local pressure modifications due to EHD pressure generation as the dent passes through the Hertzian region.

\section{REFERENCES}

1. Littmann, W. E. and Widner, R. L., "Propagation of Contact Fatigue from Surface and Subsurface Origins," Trans. of ASME, Journal of Basic Engineering, Sept. 1966, pp. 624-636.

2. Martin, J. A. and Eberhardt, A. D., "Identification of Potential Failure Nuclei in Rolling Contact Fatigue," Trans. of ASME, Journal of Basic Engineering, Vol. 89, Dec. 1967. pp. 932-942.

3. Chiu, Y. P., Borgese, S., McCool, J. I., and Tallian, T. E., "Refinement and Evaluation of Rolling Bearing Load-Life Model," Final Technical Report RADC-TR-69-264, Nov. 1970. 
4. Chiu, Y. P., Tallian, T. E., and McCool, J. I., "An Engineering Model of Spalling Fatigue in Rolling Contact, I. The Subsurface Model," Wear, Vol. 17, 1971, pp. 433-440.

5. Tallian, T. E. and McCool, J. I., "An Engineering Model of Spalling Fatigue Failure in Rolling Contact, II. The Surface Model," Wear, Vol. 17, 1971, pp. 447-461.

6. Tallian, T. E., "An Engineering Model of Spalling Fatigue Failure in Rolling Contact, III. Engineering Discussion and Illustrative Examples," Wear, Vol. 17,1971 , pp. 463-480.

7. Tallian, T. E., "The Theory of Parti $\iota_{2}$ Elastohydrodynamic Contacts," Wear, Vol. 21, 1972, pp. 49-101.

8. Parker, R. J. and Zaretsky, E. V., "Effect of Residual Stresses Induced by Prestressing on Rolling-Element Fatigue Life." NASA TN D-6995, Oct. 1972 .

9. Parker, R. J., "Correlation of Magnetic Perturbation Inspection Data with Rolling Element Bearing Fatigue Results," Trans. of ASME, Journal of Lubrication Technology, Vol. 97, Series F, No. 2, April 197 pp. 151-158.

10. Leibensperger, R. L. and Brittain, T. M., "Shear Stresses Below Asperities in Hertzian Contact as Measured by Photoelasticity," Trans. of ASME, Journal of Lubrication Technology, Vol. 95, Series F, No. 3, July 1973, pp. 277-286.

11. Liu, J. Y., Tallian, T. E., and McCool, J. I., "Dependence of Bearing Fatigue Life on Film Thickness to Surface Roughness Ratio," Trans. ASLE, Vol. 18, No. 2, April 1975, pp. 144-152.

12. See Discussion by Berthe, D. and Godet, M., Lubrication Engineering, Vol. 32, No. 1, Jan. 1976, pp. 35-36. 
13. Tallian, T. E., "Prediction of Rolling Contact Fatigue Life on Contaminated Lubricant: Part I - Mathematical Model," ASME Paper No. 75Lub-37, presented at ASME/ASLE Joint Lubrication Conference, Miami Beach, Florida, Oct. 21-23, 1975.

14. Tallian, T. E., "Prediction of Rolling Contact Fatigue Life in Contaminated Lubricant: Part II - Experimental," ASME Paper No. 75-Lub-38, presented at ASME/ASLE Joint Lubrication Conference, Miami Beach, Florida, Oct. 21-23, 1975.

15. Wedeven, L. D., "Traction and Film Thickness Measu rements Under Starved Elastohydrodynamic Conditions," Trans. of ASME, Journal of Lubrication Technology, Vol. 97, Series F, No. 2, April 1975, pp. $321-329$.

16. Wedeven, L. D., "Effect of Starvation on Film Thickness and Traction Under Elastohydrodynamic Rolling ard Sliding Conditions," NASA TN D-8087, Oct. 1975.

17. Wedeven, L. D.; Evans, D.; and Cameron, A.: Optical Analysis of Ball Bearing Starvation. J. Lubr. Tech., Trans. ASME, Ser. F, vol. 93, no. 3 , July 1971 , pp. $349-363$.

18. Foord, C. A.; Wedeven, L. D.; Westlake, F. J.; and Cameron, A.: Optical Elastohydrodynamics. Proc. Inst. Mech. Engrs., Vol. 184, pt. 1, 1969-1970, pp. 487-505.

19. Chiu, Y. P. and Liu, J. Y., "An Analytical Study of the Stress Concentration A round a Furrow Shaped Surface Defect in Rolling Contact," Trans. ASME, Jsurnal of Lubrication Technology, Vol. 92, Series F, No. 2, April 1970, pp. 258-263.

20. Wedeven, L. D., "What is EHD?," Lubrication Engineering, Vol. 31, No. 6, June 1975, pp. 291-296. 
21. Jackson, A. and Cameron, A., "An Interferometric Study of the EHL of Rough Surfaces," Trans. ASLE, Vol. 19, No. 1, Jan. 1976, pp. 50-60.

22. See discussion of ref. 21 .

23. Tallian, T. E., "Pressure and Traction Rippling in Elastohydrodynamic Contact of Rough Surfaces," Trans. ASME, Journal of Lubrication Technology, Vol. 96 , Series F, No. 3, July 1974 , pp. 398-409 
TABLE I. - BEARING MATERIAL PROPERTIES

\begin{tabular}{|l|r|r|}
\hline & \multicolumn{1}{|c|}{ Ball } & \multicolumn{1}{|c|}{ Disk } \\
\hline Material & 52100 Steel & Sapphire \\
Compressive strength & $1.4 \times 10^{9} \mathrm{~N} / \mathrm{m}^{2}$ & $2 \times 10^{9} \mathrm{~N} / \mathrm{m}^{2}$ \\
Elastic modulus & $204 \times 10^{9} \mathrm{~N} / \mathrm{m}^{2}$ & $465 \times 10^{9} \mathrm{~N} / \mathrm{m}^{2}$ \\
Poisson's ratio & 0.3 & 0.47 \\
Hardness & $65 \mathrm{R}_{\mathrm{c}}$ & 9 Moh \\
Roughness & $0.08 \mu \mathrm{m} \mathrm{rms}$ & Optical polish \\
\hline
\end{tabular}

TABLE II. - PROPERTIES OF TEST FLUIDS

\begin{tabular}{|l|r|r|}
\hline & $\begin{array}{r}\text { Synthetic paraffinic oil } \\
\text { (XRM109F3) }\end{array}$ & $\begin{array}{c}\text { Traction fluid } \\
\text { (MCS 1218) }\end{array}$ \\
\hline Viscosity & $45,830 \mathrm{cs}$ at $17.8^{\circ} \mathrm{C}$ & $1418 \mathrm{cs}$ at $37.8^{\circ} \mathrm{C}$ \\
& $493 \mathrm{cs}$ at $37.8^{\circ} \mathrm{C}$ & $180 \mathrm{cs}$ at $58.3^{\circ} \mathrm{C}$ \\
& $42.6 \mathrm{cs}$ at $98.9^{\circ} \mathrm{C}$ & $18.37 \mathrm{cs}$ at $98.9^{\circ} \mathrm{C}$ \\
Density & $0.8389 \mathrm{~g} / \mathrm{cm}^{3}$ at $37.8^{\circ} \mathrm{C}$ & $0.94 \mathrm{~g} / \mathrm{cm}^{3}$ at $21^{\circ} \mathrm{C}$ \\
& $0.8082 \mathrm{~g} / \mathrm{cm}^{3}$ at $93.3^{\circ} \mathrm{C}$ & \\
& $0.7777 \mathrm{~g} / \mathrm{cm}^{3}$ at $149^{\circ} \mathrm{C}$ & \\
Pressure & $1.99 \times 10^{-8} \mathrm{~m}^{2} / \mathrm{N}$ at $37.8^{\circ} \mathrm{C}$ & $5.8 \times 10^{-8} \mathrm{~m}^{2} / \mathrm{N}$ at $58.3^{\circ} \mathrm{C}$ \\
vis. coeff. & $1.55 \times 10^{-8} \mathrm{~m}^{2} / \mathrm{N}$ at $99^{\circ} \mathrm{C}$ & \\
& $1.29 \times 10^{-8} \mathrm{~m}^{2} / \mathrm{N}$ at $140^{\circ} \mathrm{C}$ & \\
Refractive index & \multicolumn{2}{|c}{1.4689}
\end{tabular}

TABLE III. - VALUES OF INLET DIMENSIONS

\begin{tabular}{|r|r|r|r|}
\hline $\begin{array}{c}\mathrm{h}_{0}, \\
\mu \mathrm{m}\end{array}$ & $\begin{array}{c}\varphi, \\
\mathrm{deg}\end{array}$ & $\begin{array}{c}\mathrm{h}_{\mathrm{b}} \\
\mu \mathrm{m}\end{array}$ & $\begin{array}{c}\mathrm{s}_{\mathrm{f}}, \\
\mu \mathrm{m}\end{array}$ \\
\hline 0.14 & 0.71 & 1.26 & 90 \\
.30 & .91 & 2.70 & 151 \\
.78 & 1.25 & 7.02 & 286 \\
\hline
\end{tabular}




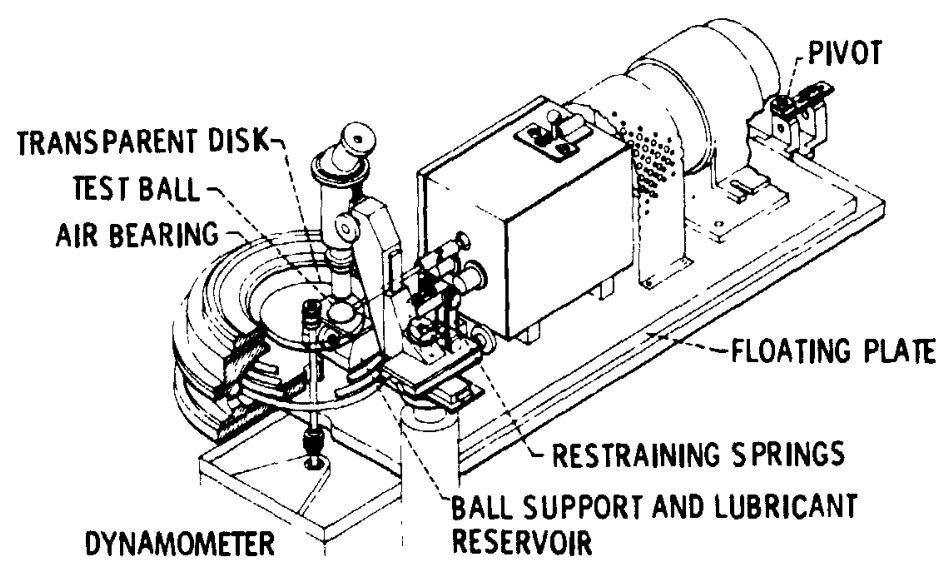

Figure 1. - Optical EHD rig.

0
0
0
-3
1
1

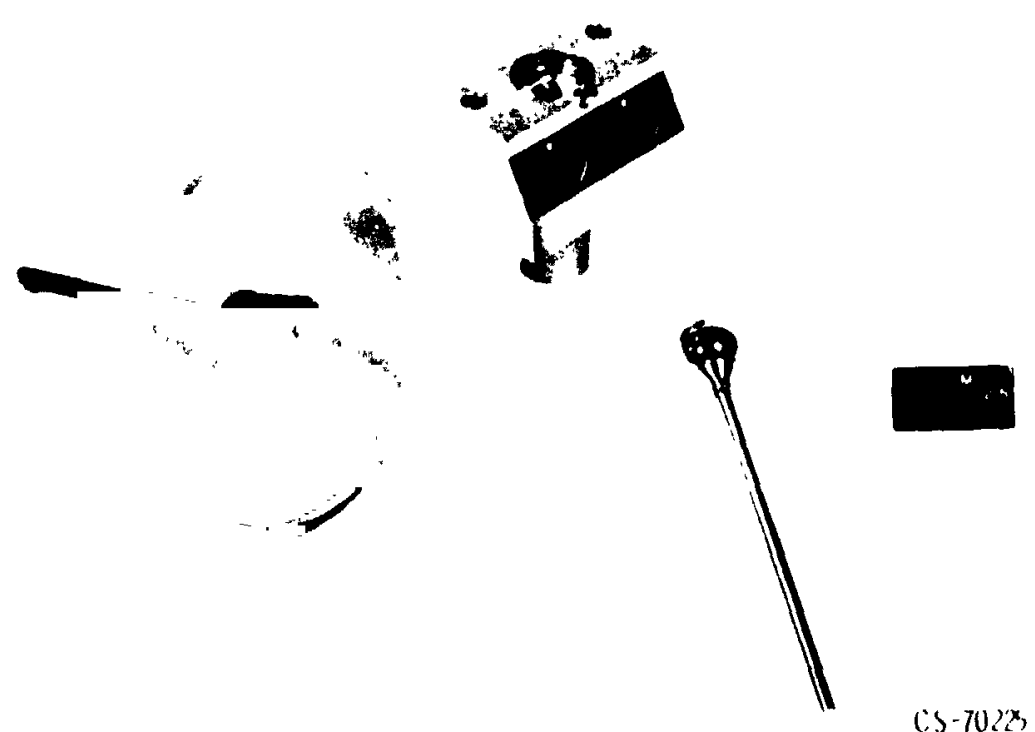

Figure 2. - Test bearing specimens. 



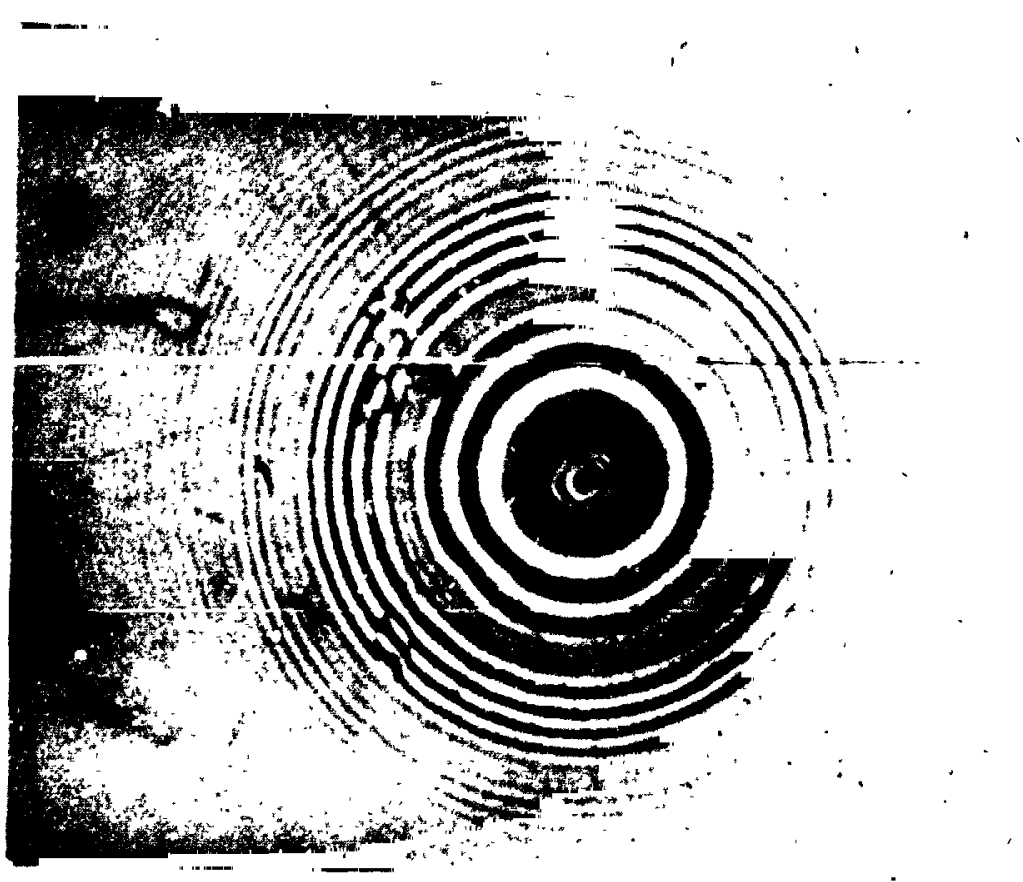

Figure 5. - Photomicrograph of uent 1 in dry static contact under low load.

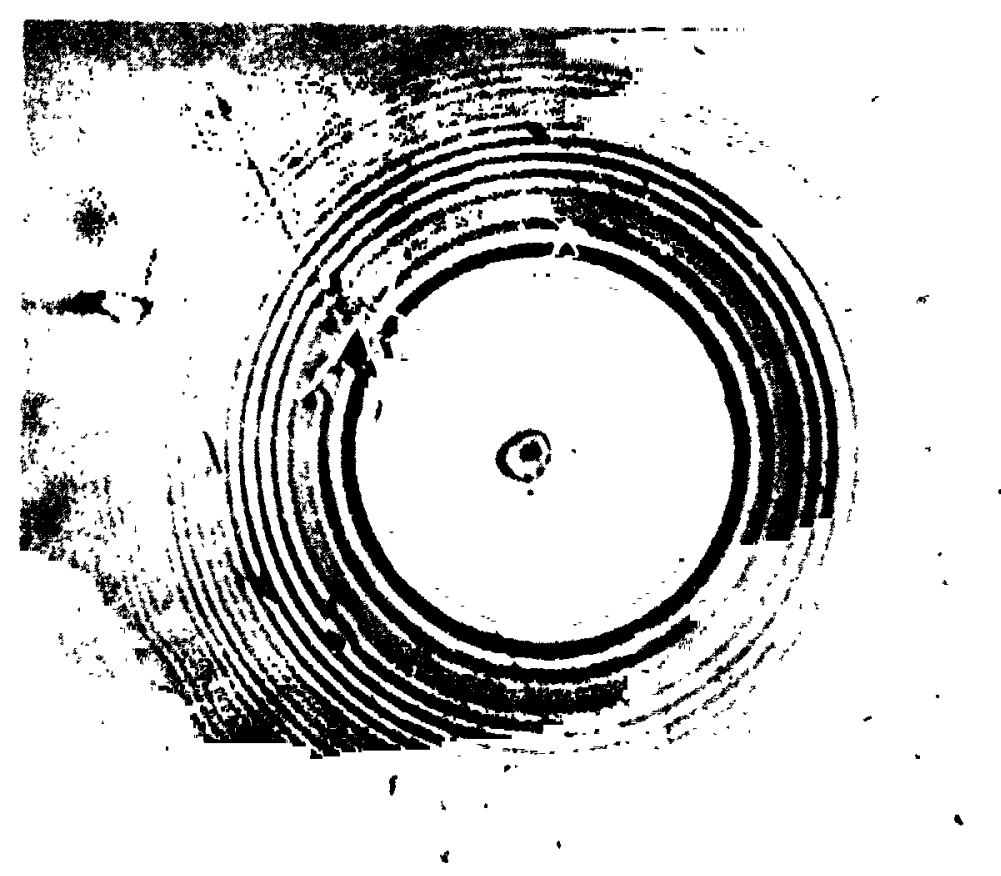

Figure 6. - Photomicrograph of sent in dry static contact under high load, $37.8 \mathrm{~N}$ $P_{\max }=1.2 \times 10^{9} \mathrm{~N} / \mathrm{m}^{2} 1175000 \mathrm{psi}$. 


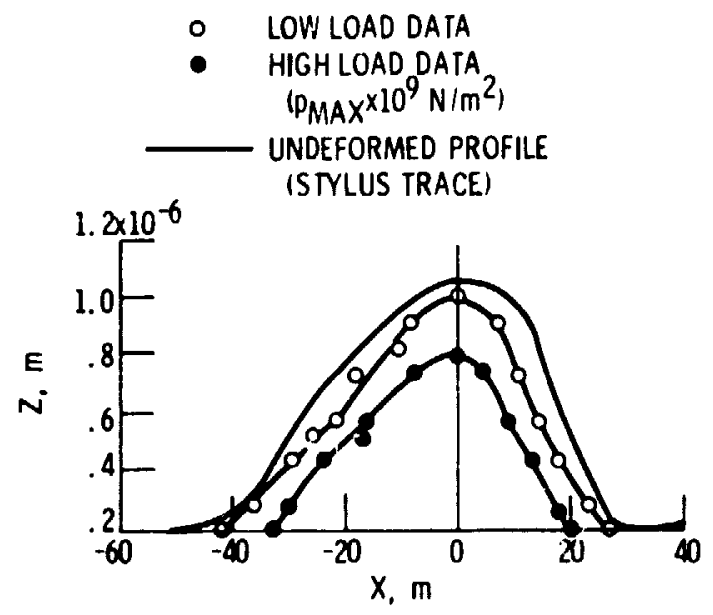

Figure 7. - Comparison of dent cross sectional profiles fol two loads under dry static contact conditions with undeformed profile.

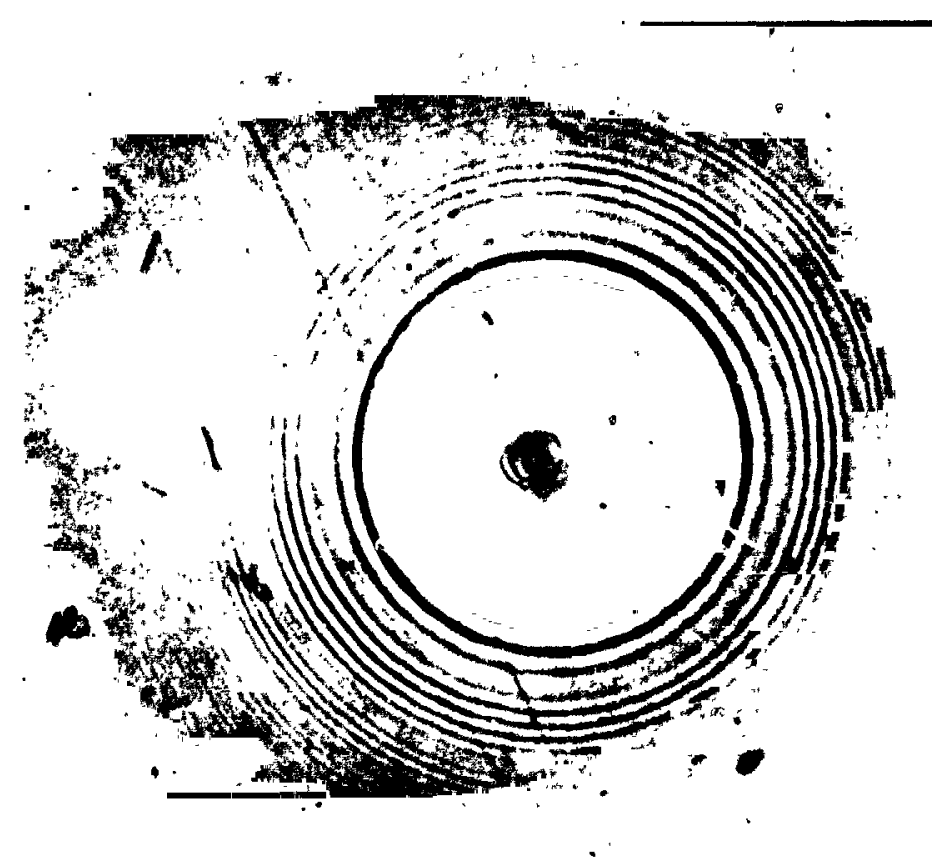

Figure 8. - Photomicrograph of dent in lubricated static conlact: load, $37.8 \mathrm{~N}$ : $P_{\text {max }}=1.2 \times 10^{9} \mathrm{~N} / \mathrm{m}^{2}$. 


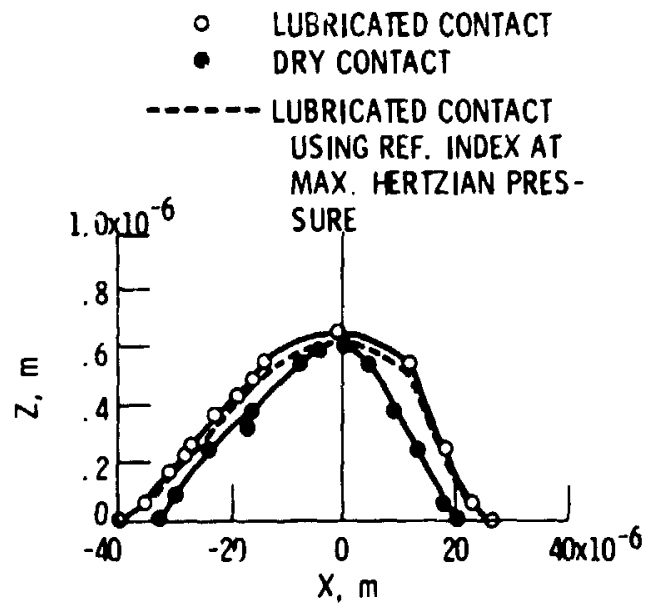

Figure 9. - Dent cross-sectional profiles for dry and lubricated contact conditions; load, 37.8 N, $P_{\max }=$ 1. $2 \times 10^{9} \mathrm{~N} / \mathrm{m}^{2}$.
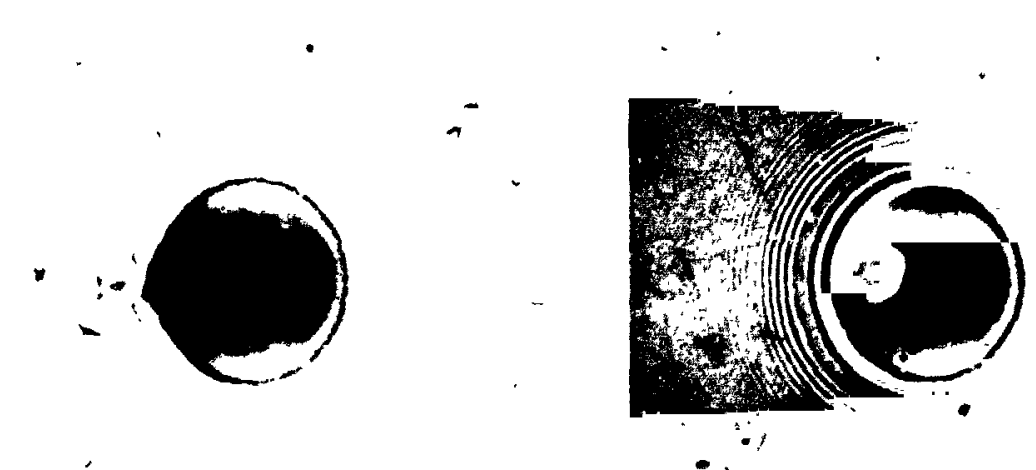

(a)

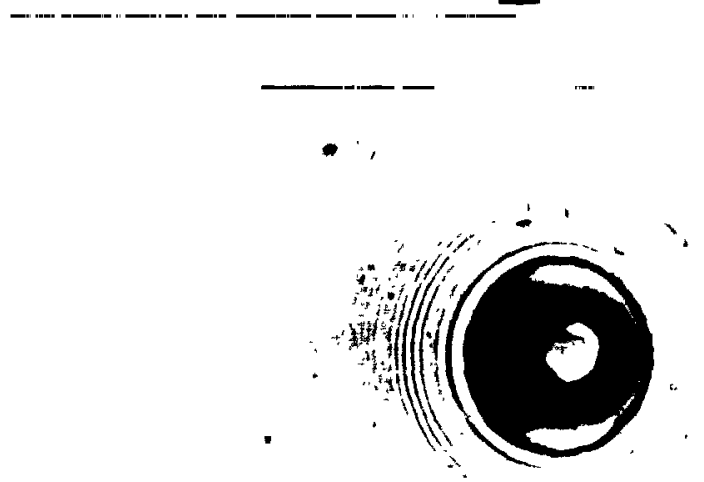

(c)

Figure 10. - Photomicrographs of dent in three different positions: $h_{0}=0.14 \mu \mathrm{m}, p_{\max }=1.2 x 10^{9} \mathrm{~N} / \mathrm{m}^{2}, \mathrm{u}=$ $0.0134 \mathrm{~m} / \mathrm{s}$. 

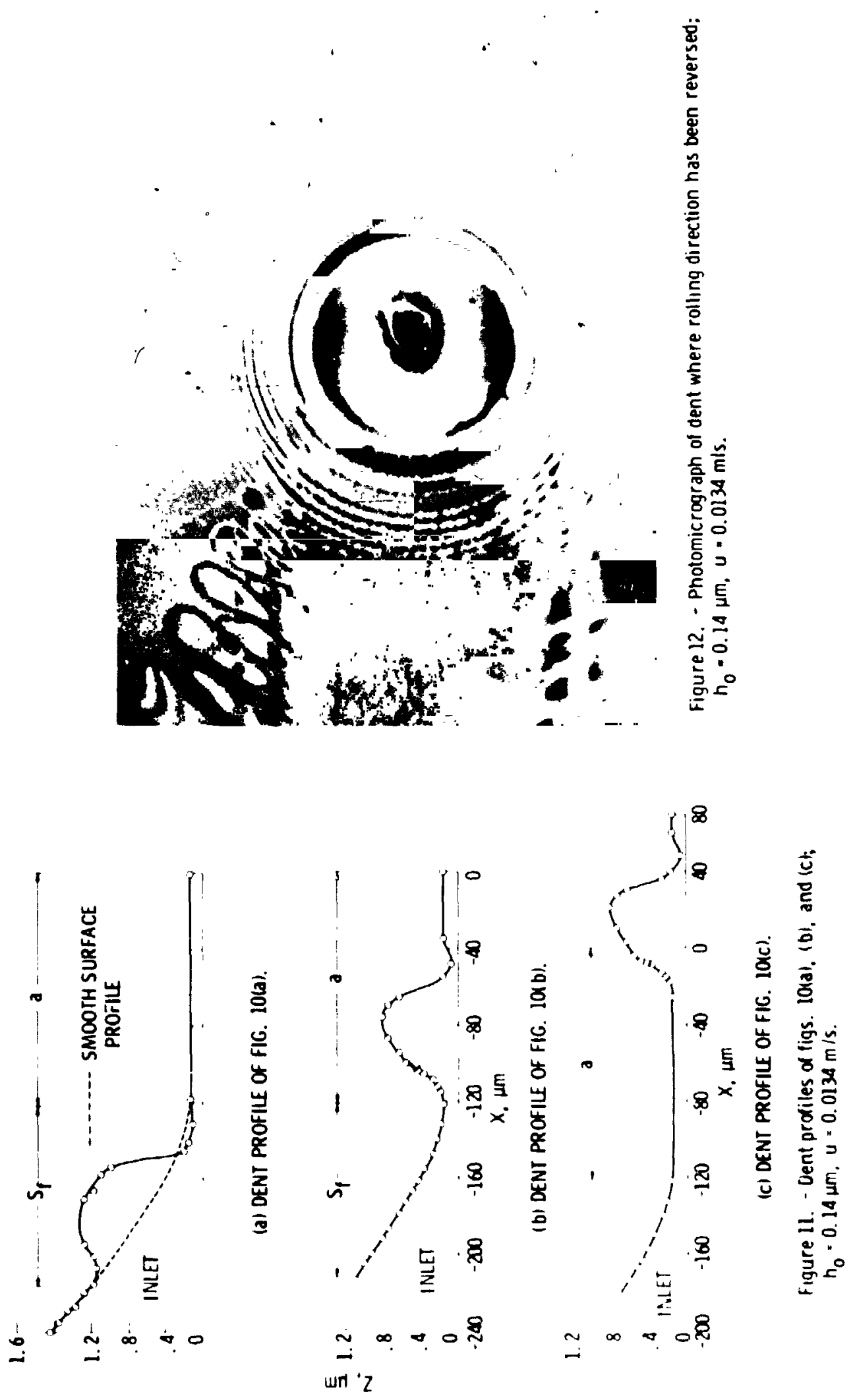


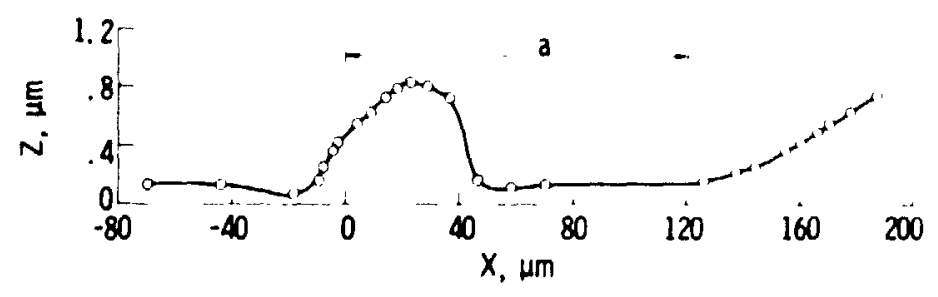

Figure 13. - Dent profile of Fig. 12 where rolling directior. has been reversed, $h_{0} \cdot 0.14 \mu \mathrm{m}, u=0.0134 \mathrm{~m} / \mathrm{s}$.
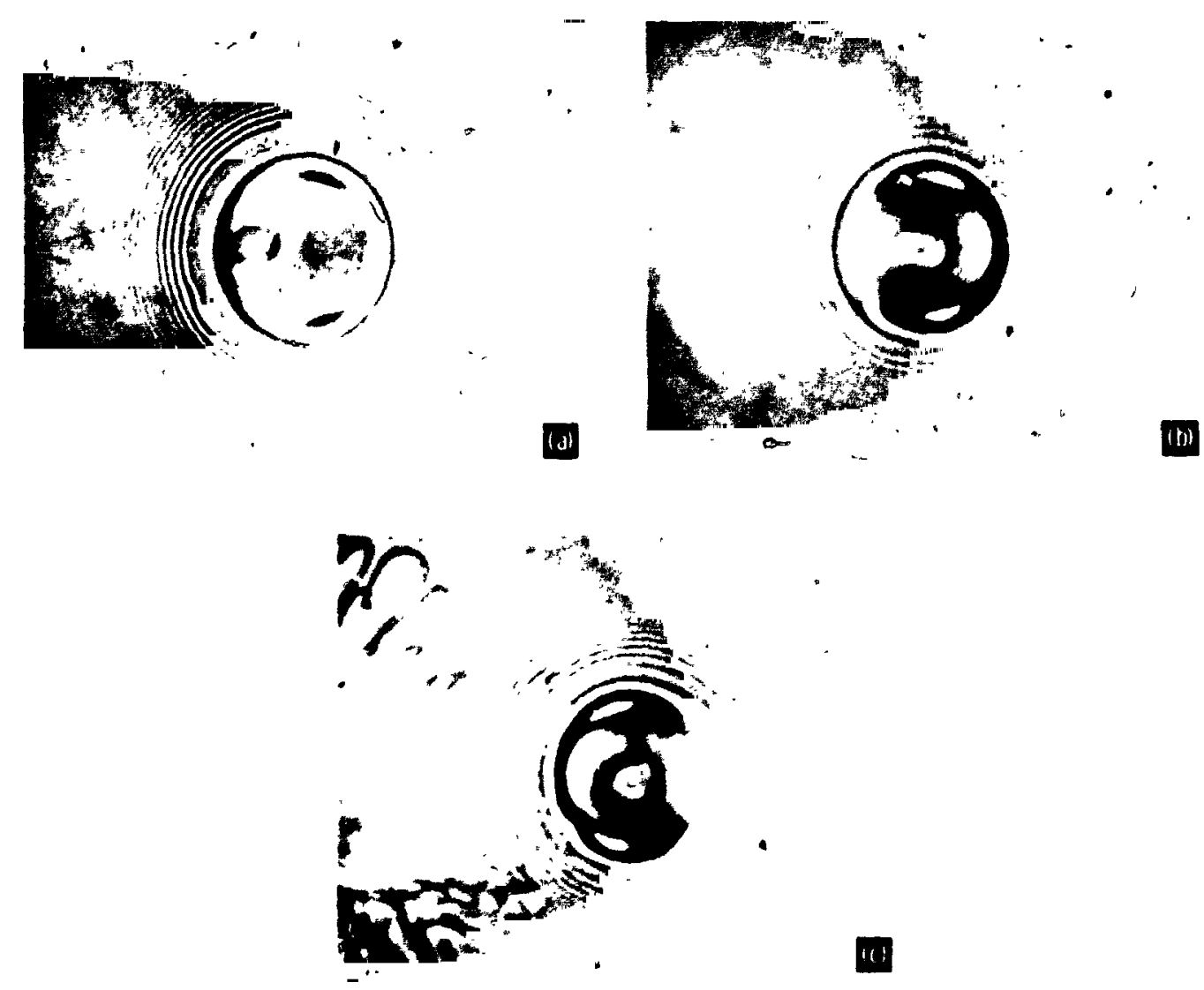

$11 !$

Figure 14. $-(a)$ and (b): Photomicrograph of dent in two different locations $h_{0}=0.30 \mu m, \rho_{\max }=1.2 x ! 0^{4}$ $\mathrm{N} / \mathrm{m}^{2}, u \cdot 0.0432 \mathrm{~m} / \mathrm{s}$; (c) rolling direction reversed. 

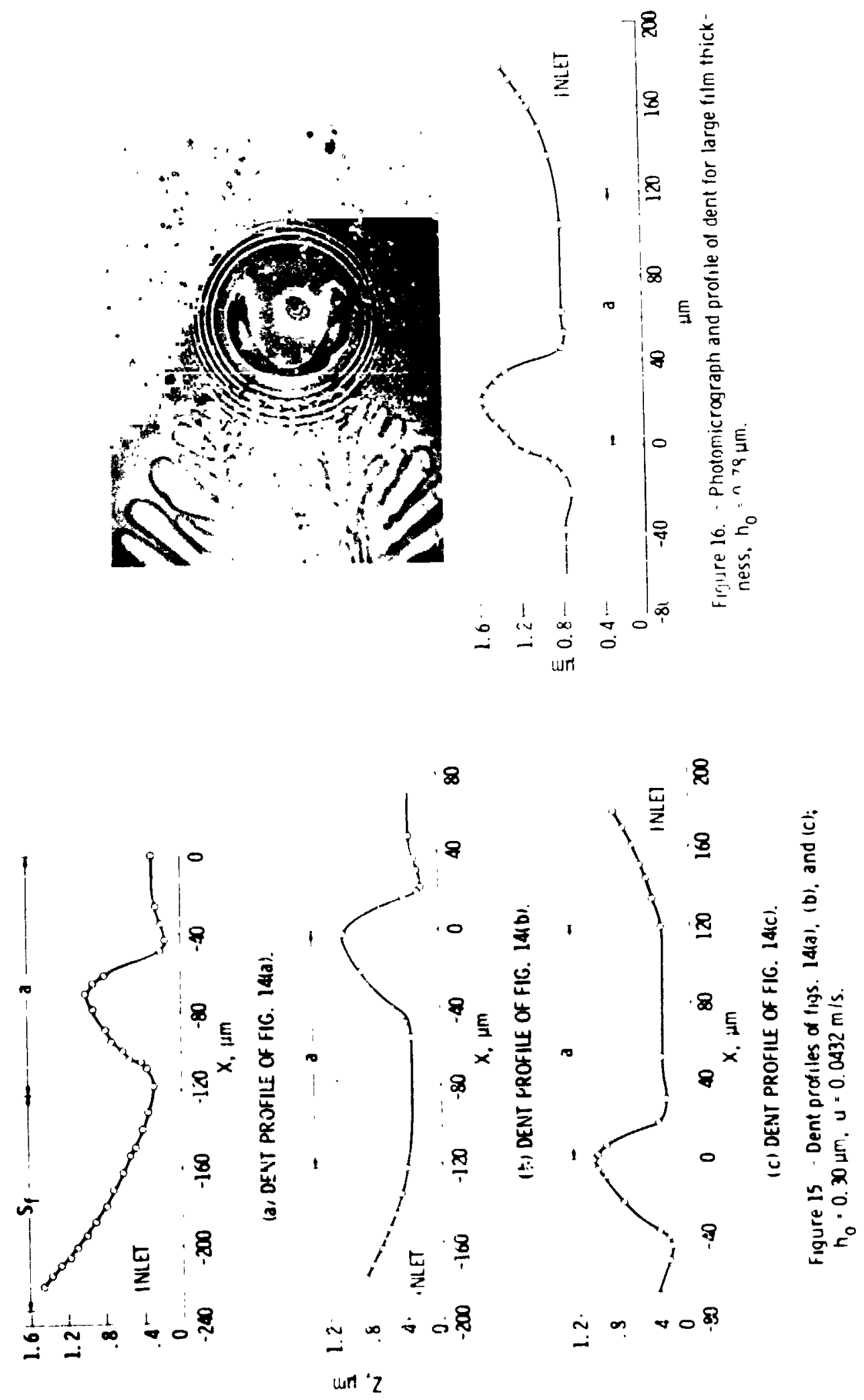

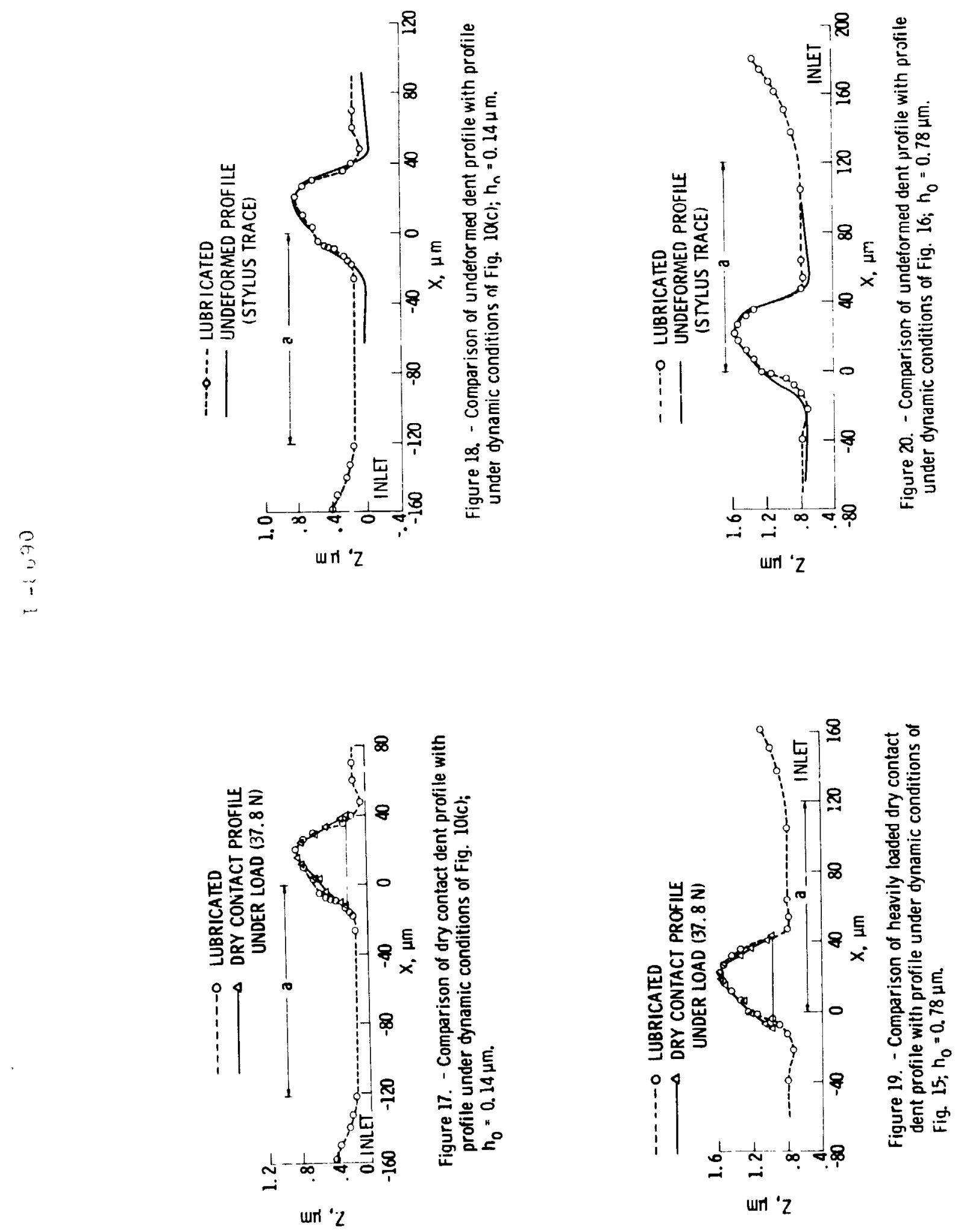


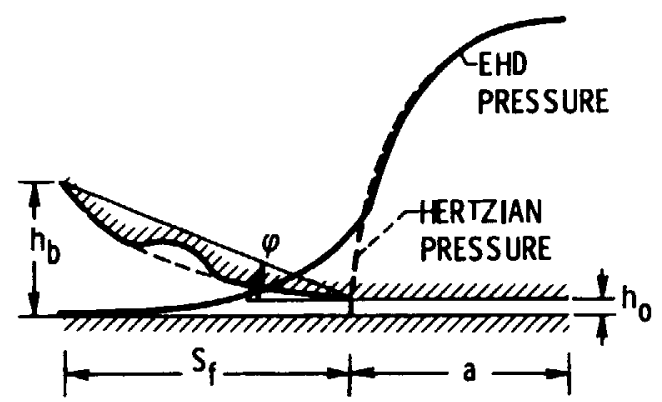

Figure 21. - Schematic drawing showing characteristic inlet dimensions.
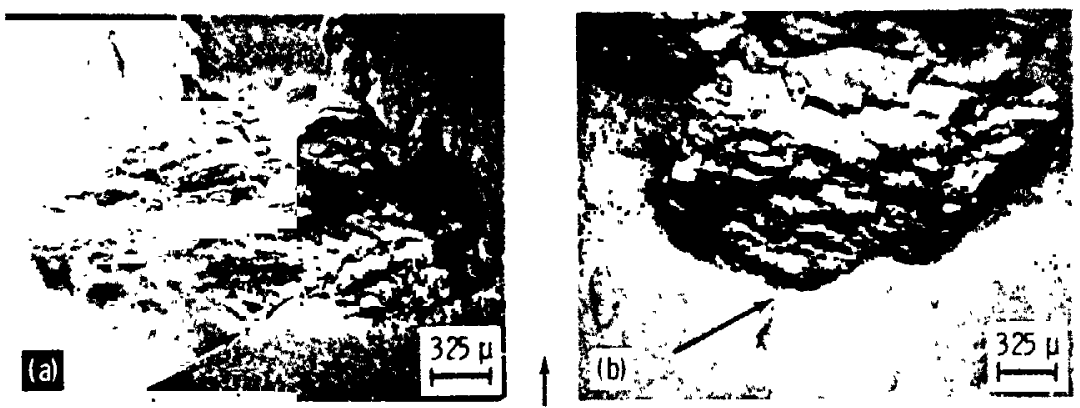

DIRECTION OF BALL TRAVEL
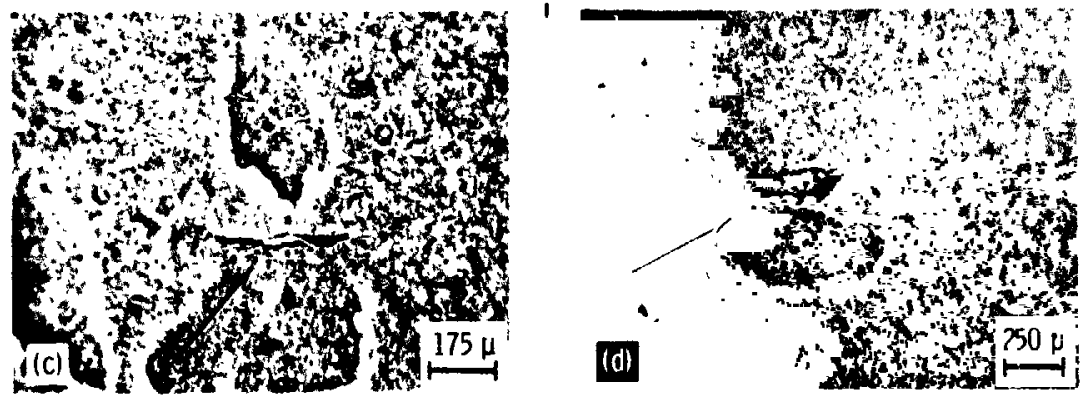

Figure 22. - Spalls (a) and (b) and pre-spall cracking (c) and (d) at surface dents. (Arrows indic ate spall formation at trailing edge of dents.) 


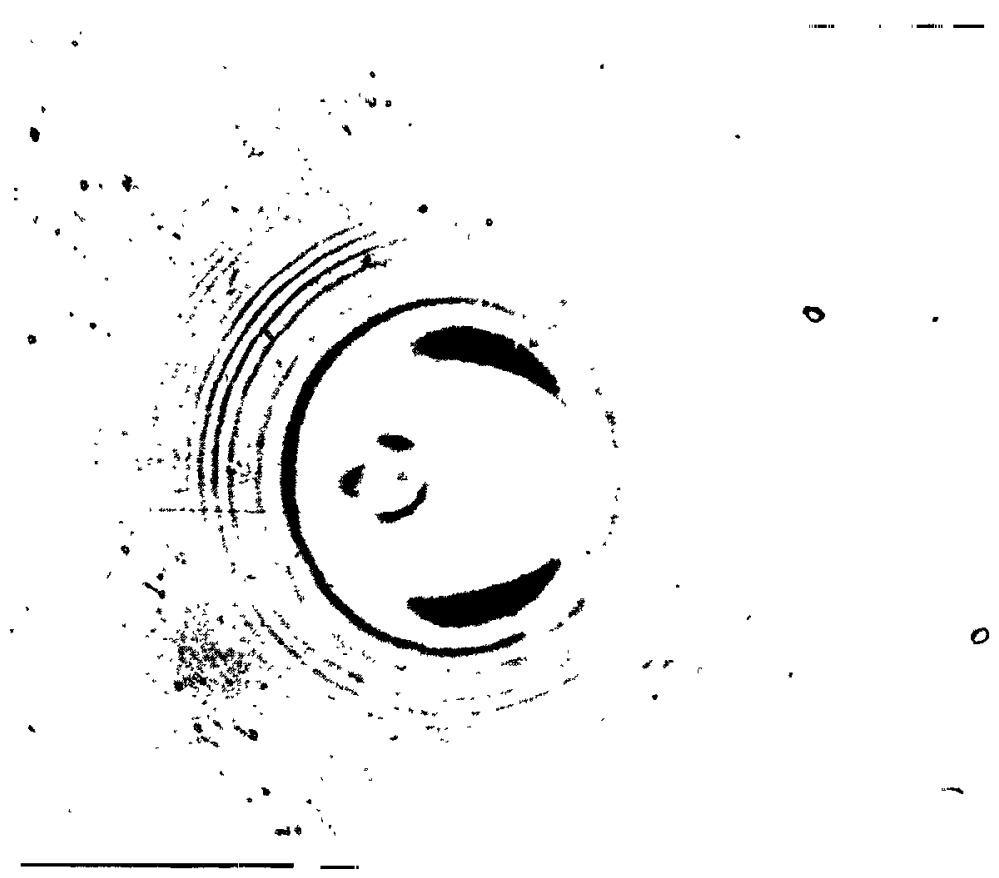

Figure 23. - Photomicrograph of dent under combined rolling and sliding conditions; $h_{0}=0.26 \mu \mathrm{m}$.

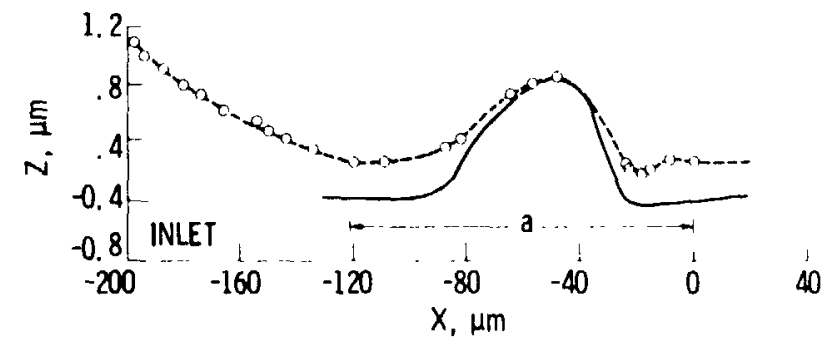

Figure 24. - Comparison of undeformed dent profile with rolling/sliding profile of Fig. $23 ; h_{0}=0.26 \mu \mathrm{m}$. 